\title{
SOMATIC COMORBIDITIES: HOW IMPORTANT ARE THEY FOR STIGMA AND QUALITY OF LIFE OF PATIENTS WITH REFRACTORY EPILEPSY
}

\author{
E. Viteva \\ Department of Neurology, University of Medicine - Plovdiv, Bulgaria
}

\begin{abstract}
Purpose: To assess the impact of somatic comorbidities on stigma and the quality of life of Bulgarian patients with refractory epilepsy.
\end{abstract}

Methods: We have studied 92 adult patients with refractory epilepsy, without cognitive impairment, progressive somatic, neurological disease or recent seizures. All participants fulfilled a 3-item stigma scale and QOLIE-89 questionnaire.

Results: The study participants (61.96\% men) had a mean disease duration $42.34 \pm 1.28$ years. Seventy three patients $(77.17 \%)$ had focal epilepsy, 21 (22.83\%) had generalized epilepsy. The etiology of the greatest percentage of participants (39.13\%) was unknown, $35.87 \%$ had symptomatic epilepsy. We found stigmatization in $43.48 \%$ of the patients, $29.35 \%$ of them were severely stigmatized. There were concomitant somatic diseases in $40.22 \%$ of patients, in $16.31 \%$ - from more than one system. We proved that somatic comorbidities did not have influence on the overall score of QOLIE-89 P > $0.05(F=2.64)$ and on perceived stigma $P>0.05(\chi 2=2.36)$.

Conclusion: Somatic comorbidities in patients with refractory epilepsy do not correlate negatively with perceived stigma and does not influence the overall score of their quality of life.

Key words: comorbidities, stigma, refractory epilepsy, quality of life, impact.

\section{INTRODUCTION}

Health-related stigma is based on a special characteristic of a health problem or a state ${ }^{1}$. In persons with epilepsy stigma is a result of the unpredictability of seizures and social exclusion ${ }^{2}$ and it worries the patient more than the disease itself. A great number of studies have been performed in search of stigma determinants, but there are no data in literature about the impact of somatic comorbidities which present as a weighty, but often unrecognized burden in patients with epilepsy ${ }^{3}$.

Epilepsy has a great influence on all aspects of quality of life, which is exercised directly - by affecting the physical and mental health, and indirectly - by introducing limitations and decreasing the opportunities for taking part in quality of life improving activities. In studies about quality of life of patients with epilepsy and its determinants somatic comorbidities have received limited attention. The results about their influence on the different aspects of life quality are controversial and vary from lacking impact ${ }^{4}$ to a significant predictive role ${ }^{5-8}$.

\footnotetext{
${ }^{*}$ Corresponding author:

Email: eiviteva@abv.bg

http://dx.doi.org/10.20530/IJTA_31_14-17

ISSN 2320-138X @ 2016
}

No study of somatic comorbidities and their impact on stigma and quality of life of patients with epilepsy has been performed in Bulgaria

Purpose of the study: Assessment of the impact of somatic comorbidities on perceived stigma and the quality of life of Bulgarian patients with refractory epilepsy (RE).

\section{PATIENTS AND METHODS}

The study was performed with the participation of a representative selection of 157 patients who attended the Clinic of Neurology at the University Hospital in Plovdiv, Bulgaria for a regular examination or in cases of unsatisfactory seizure control or adverse events from treatment.

All study procedures were performed after the approval of the Local Ethics Commission at the University of Medicine, Plovdiv. Every patient was introduced to the study design and signed an informed consent form before participation in the study procedures.

We used the following inclusion criteria: a signed informed consent form; age between 18 and 65 years; a diagnosis of refractory epilepsy; lack of cognitive impairment based on Evaluation Rapide des Fonctions Cognitives ${ }^{9}$ with a score $<47$ in patients up to 60 years of age and primary education or < 46 in patients between 60 and 65 years of age and less than a primary education or illiteracy; lack of a simple or complex partial 
seizure in the last 4 hours; and lack of generalized tonic-clonic seizures in the last 24 hours. We accepted epilepsy as refractory in cases in which adequate seizure control with at least two potentially effective anti-epileptic drugs prescribed as mono- or poly-therapy at maximal tolerated doses had not been achieved. After excluding 2 patients older than 65 years, 5 patients with a simple or complex partial seizure in the last 4 hours or a generalized tonic-clonic seizure in the last 24 hours, and 58 patients with cognitive impairment, 92 patients with RE remained in the study.

The data were collected by means of a purposeful interview and examination of the patients' medical documentation. All study participants completed the stigma scale (Hyman, 1971) and QOLIE-89. The stigma scale consists of three questions pertaining to patients' opinions about the attitudes of people. The possible answers are "yes" and "no." The severity of stigmatization depends on the number of positive answers. If there was one affirmative response, we accepted the patient as stigmatized. The scale scores are: 0 = "none", 1 = "mild", 2 = "moderate", and 3 = "severe". The scale has been applied by Jacoby et al. ${ }^{10}$ in patients with epilepsy and is known to have satisfactory convergent validity and internal consistency ${ }^{1}$.

QOLIE-89 is the most understandable and the most widely used instrument for quality of life assessment in patients with epilepsy. It is one of the scales including the greatest number of associated with epilepsy factors. QOLIE-89 has been approved as appropriate for research and it is completed for 45 minutes. This scale enables the discrimination of minimally expressed but significant life quality changes in these patients. QOLIE-89 contains 89 items which are distributed in 17 subscales which tap the following health concepts: health perceptions (6 items), overall QOL (2 items), physical health (10 items), role limitations due to physical problems (5 items), limitations due to emotional problems (5 items), pain (2 items), work/driving/social function (11 items), energy/fatigue (4 items), emotional wellbeing ( 5 items), attention/concentration ( 9 items), health discouragement ( 2 items), seizure worry ( 5 items), memory (6 items), language (5 items), medication effects (3 items), social support (4 items), social isolation ( 2 items), change in health over the preceding year ( 1 item), satisfaction with sexual relations ( 1 item). The 17 subscales characterize 4 basic factors directed towards

epilepsy, physical, mental and social health. The Bulgarian version was validated and its reliability, internal consistency and validity were proven by Viteva et al. ${ }^{11}$

The collected primary information was checked, encoded, and entered into a computer database for statistical analysis. Data were processed using SPSS 17.0. Results for quantitative variables were expressed as mean \pm SE (standard error) and results for qualitative variables as percentages. The associations of somatic comorbidities with perceived stigma and the overall score of QOLIE-89 were analysed by means of $\chi^{2}$ - Test and $F$ - test.

\section{RESULTS}

Thirty-five (38.04\%) of the study participants were men; the remaining 57 (61.96\%) were women. The mean patients' age was $42.34 \pm 1.28$ years. The mean disease duration was $26.32 \pm 1.28$ years. The findings concerning epilepsy, somatic comorbidities, and stigma are shown in Table 1.

The most frequent somatic comorbidities were cardiovascular (18.48\%), gastro-intestinal (8.7\%), rheumatic (6.52\%), and pulmonary (5.43\%) diseases.

The mean overall score of QOLIE-89, given by the patients, was $62.75 \pm 1.92$.

Table 1. Findings concerning epilepsy, somatic comorbidities, and stigma of the study participants

\begin{tabular}{lcc}
\hline Findings & $\mathbf{N}$ & $\mathbf{P}(\%) \pm \mathbf{S E}$ \\
\hline Type of epilepsy & & \\
- focal & 71 & $77.17 \pm 4.40$ \\
- generalized & 21 & $22.83 \pm 4.40$ \\
Etiology of epilepsy & & \\
- genetic & 23 & $25.00 \pm 4.54$ \\
- structural/ metabolic & 36 & $39.13 \pm 5.12$ \\
- unknown & 33 & $35.87 \pm 5.03$ \\
Stigma & & \\
- no & 52 & $56.52 \pm 5.20$ \\
- mild & 8 & $8.70 \pm 2.95$ \\
- moderate & 5 & $5.43 \pm 2.38$ \\
- severe & 27 & $29.35 \pm 4.77$ \\
Somatic comorbidities & & \\
- no & 55 & $59.78 \pm 5.14$ \\
- from 1 system & 22 & $23.91 \pm 4.47$ \\
- from $>1$ system & 15 & $16.31 \pm 3.87$ \\
\hline * SE - standard error, & P $(\%)$ & - percentage of \\
patients & &
\end{tabular}


Table 2. Association of somatic comorbidities with perceived stigma in patients with RE

\begin{tabular}{|c|c|c|c|c|c|c|}
\hline \multicolumn{2}{|c|}{ Somatic comorbidities } & \multicolumn{5}{|c|}{ Stigma } \\
\hline & & No & Mild & Moderate & Severe & Total \\
\hline \multirow[t]{2}{*}{ No } & $\mathbf{N}$ & 31 & 3 & 3 & 18 & 55 \\
\hline & p\% & $56.4 \%$ & $5.5 \%$ & $5.5 \%$ & $32.7 \%$ & $100.0 \%$ \\
\hline \multirow[t]{2}{*}{ From 1 system } & $\mathbf{N}$ & 13 & 3 & 1 & 5 & 22 \\
\hline & p\% & $59.1 \%$ & $13.6 \%$ & $4.5 \%$ & $22.7 \%$ & $100.0 \%$ \\
\hline \multirow[t]{2}{*}{ From > 1 system } & $\mathbf{N}$ & 8 & 2 & 1 & 4 & 15 \\
\hline & p\% & $53.3 \%$ & $13.3 \%$ & $6.7 \%$ & $26.7 \%$ & $100.0 \%$ \\
\hline \multirow[t]{2}{*}{ Total } & $\mathbf{N}$ & 52 & 8 & 5 & 27 & 92 \\
\hline & p\% & $56.5 \%$ & $8.7 \%$ & $5.4 \%$ & $29.3 \%$ & $100.0 \%$ \\
\hline
\end{tabular}

Table 3. Association of somatic comorbidities with the overall score of QOLIE-89 in patients with RE

\begin{tabular}{llllcccc}
\hline $\begin{array}{l}\text { Somatic } \\
\text { comorbidities }\end{array}$ & N & Mean & SE & \multicolumn{2}{c}{$\mathbf{9 5 \%} \mathbf{C l}$} & Minimum & Maximum \\
\cline { 5 - 7 } & & & & $\begin{array}{l}\text { Lower } \\
\text { bound }\end{array}$ & $\begin{array}{l}\text { Upper } \\
\text { bound }\end{array}$ & & \\
\hline No & 55 & 66.19 & 2.64 & 60.90 & 71.48 & 15.14 & 96.74 \\
From 1 system & 22 & 58.96 & 2.96 & 52.80 & 65.12 & 36.15 & 87.80 \\
From > 1 system & 15 & 55.61 & 4.59 & 45.76 & 65.46 & 21.19 & 81.74 \\
Total & 92 & 62.74 & 1.92 & 58.92 & 66.55 & 15.14 & 96.74 \\
\hline
\end{tabular}

The analysis of associations of somatic comorbidities with perceived stigma and the overall score of QOLIE-89 are shown in Table 2 and Table 3.

\section{DISCUSSION}

The overall assessment of patients with epilepsy requires paying attention to their somatic comorbidities. The limited number of studies on this aspect is a probable explanation of the controversial results in literature. Some investigators support the statement that somatic comorbidities occur more frequently in people with epilepsy than in the general population ${ }^{3}$. Jalava et al., however, have shown that there is no significantly increased risk for somatic comorbidities in patients with epilepsy compared to controls ${ }^{12}$.

In our study we have found at least one somatic concomitant disease in 37 (40.22\%) patients which is similar to the results of Adelayo et al. $(30.4 \%)^{13}$. No studies about the impact of somatic comorbidities on stigma in people with epilepsy have been performed so far. Our results confirmed no association of concomitant somatic diseases with perceived stigma in patients with refractory epilepsy.

Few investigators have studied the influence of comorbidities on quality of life perception of people with epilepsy. Our study results confirm the conclusion of Tlusta et al. who describe no such influence ${ }^{4}$. A possible explanation of this finding is the thesis conclusion of Fernandez et al., that the presence of associated comorbidities in patients has no significant impact whatsoever on the clinical outcome, although it concerns only patients with idiopathic etiology of epilepsy ${ }^{14}$. On the contrary, other investigators support the negative impact of comorbidities on quality of life ${ }^{5-}$ $8,13,15$ and indicate them as significant predictors of some (energy/fatigue and well-being) or all aspects of quality of life $e^{6,15}$. Most authors, however, describe a negative role of medical comorbidities in general, without separating somatic from neuro-psychiatric ones, the latter having an already proven significant unfavorable impact on all quality of life aspects.

\section{LIMITATIONS}

The first limitation of our study is that we investigated somatic comorbidities and their association with perceived stigma and quality of life in patients with RE. With the purpose of an adequate completion of the Stigma scale and QOLIE-89, we excluded patients older than 65 years, having cognitive impairment, and those with simple or complex partial seizures in the last 4 hours or generalized tonic-clonic seizures in the last 24 hours. The participation of no other patients but only those having access to the University Clinic of Neurology, who usually attended it for a regular examination or in cases of unsatisfactory seizure control or adverse events from treatment, is also a limitation. These limitations however, do not devaluate the results from our study. Further investigations of patients, 
having all sorts of demographic, clinical and social characteristics, are needed.

In conclusion the demonstration of no association of somatic comorbidities with perceived stigma and quality of life is important for directing efforts in studying other possible determinants of these significant characteristics of patients with refractory epilepsy with the purpose of stigma prevention and quality of life improvement.

\section{REFERENCES}

1. Van Brakel WH. Measuring health-related stigmaA literature review. Psychology, Health \& Medicine [Internet]. Informa UK Limited; 2006 Aug;11(3):307-34. Available from: http://dx.doi.org/10.1080/13548500600595160

2. De Boer HM, Mula M, Sander JW. The global burden and stigma of epilepsy. Epilepsy \& Behavior [Internet]. Elsevier BV; 2008 May;12(4):540-6. Available from: http://dx.doi.org/10.1016/j.yebeh.2007.12.019

3. Gaitatzis A, Sisodiya SM, Sander JW. The somatic comorbidity of epilepsy: A weighty but often unrecognized burden. Epilepsia [Internet]. WileyBlackwell; 2012 Jun 12;53(8):1282-93. Available from: $\quad$ http://dx.doi.org/10.1111/j.15281167.2012.03528.x

4. Tlusta E, Zarubova J, Simko J, Hojdikova H, Salek S, Vlcek J. Clinical and demographic characteristics predicting QOL in patients with epilepsy in the Czech Republic: How this can influence practice. Seizure [Internet]. Elsevier BV; 2009 Mar;18(2):859. Available from: http://dx.doi.org/10.1016/i.seizure.2008.06.006

5. Elliott JO, Lu B, Shneker B, Charyton C, Layne Moore J. Comorbidity, health screening, and quality of life among persons with a history of epilepsy. Epilepsy \& Behavior [Internet]. Elsevier BV; 2009 Jan;14(1):125-9. Available from: http://dx.doi.org/10.1016/i.yebeh.2008.10.013

6. Elsharkawy AE, May $T$, Thorbecke R, Ebner A. Predictors of quality of life after resective extratemporal epilepsy surgery in adults in longterm follow-up. Seizure [Internet]. Elsevier BV; 2009 Sep;18(7):498-503. Available from: http://dx.doi.org/10.1016/i.seizure.2009.04.010

7. Liou $\mathrm{H}-\mathrm{H}$, Chen R-C, Chen $\mathrm{C}-\mathrm{C}$, Chiu M-J, Chang $\mathrm{Y}-\mathrm{Y}$, Wang J-D. Health related quality of life in adult patients with epilepsy compared with a general reference population in Taiwan. Epilepsy Research [Internet]. Elsevier BV; 2005 May;64(3):151-9. Available from: http://dx.doi.org/10.1016/j.eplepsyres.2005.03.006

8. Pulsipher DT, Seidenberg M, Jones J, Hermann B. Quality of life and comorbid medical and psychiatric conditions in temporal lobe epilepsy. Epilepsy \& Behavior [Internet]. Elsevier BV; 2006 Nov;9(3):510-4. Available from: http://dx.doi.org/10.1016/j.yebeh.2006.07.014

9. Gil R. Neuropsychologie. L'examen neuropsychologique, Paris: Masson, 2006: 12-16.

10. MacLeod JS, Austin JK. Stigma in the lives of adolescents with epilepsy: a review of the literature. Epilepsy \& Behavior [Internet]. Elsevier BV; 2003 Apr;4(2):112-7. Available from: http://dx.doi.org/10.1016/s1525-5050(03)00007-6

11. Viteva El, Zachariev Zl, Semerdzhieva MA. Validation of the Bulgarian version of the quality of life in epilepsy inventory (QOLIE-89). Folia Med (Plovdiv). 2010 Jan-Mar;52(1):34-9. PubMed PMID: 20380285.

12. Jalava $M$, Sillanpaa $M$. Concurrent Illnesses in Adults with Childhood-Onset Epilepsy: A Population-Based 35-Year Follow-Up Study. Epilepsia [Internet]. Wiley-Blackwell; 1996 Dec;37(12):1155-63. Available from: http://dx.doi.org/10.1111/j.15281157.1996.tb00547.x

13. Adebayo PB, Akinyemi RO, Oluwole F, Ogun SA, Ogunniyi A. Impact of somatic comorbidities on quality of life of patients living with epilepsy in Sagamu, Nigeria. Acta Neurol Scand [Internet]. Wiley-Blackwell; 2014 Sep 11;130(6):387-93. Available from: http://dx.doi.org/10.1111/ane.12281

14. Fernández \&, Andrés D. Impacto de comorbilidades en el curso clínico de la epilepsia idiopática: un estudio multicéntrico. PhD thesis., Hospital Regional Dr. Teodoro Maldonado Carbo Guyaquil, Ecuador, 2014

15. Elsharkawy AE, Thorbecke R, Ebner A, May TW. Determinants of quality of life in patients with refractory focal epilepsy who were not eligible for surgery or who rejected surgery. Epilepsy \& Behavior [Internet]. Elsevier BV; 2012 Jun;24(2):249-55. Available from: http://dx.doi.org/10.1016/i.yebeh.2012.03.012 